\title{
STUDY OF CALCIUM-K NETWORK EVOLUTION FROM ANTARCTICA
}

\author{
JAGDEV SINGH \\ Indian Institute of Astrophysics \\ Bangalore 560034 \\ India
}

\begin{abstract}
To study the evolution and decay of large convective cells known as supergranules, a solar telescope was set up at Naitri, Indian permanent station in Antarctica region during the local summer months (December 1989 through Narch 1990). A continuous sequence of calcium$\mathrm{K}$-line filtergrams for 106 hours with an interval of about 10 minute was obtained. The analysis of this data indicates that most probable life time of the calcium $K$ network is about 20 hours. The life time cepends upon the size of the cell and is larger for bigger cells. The data also show that cells (of given size) associated with remanent magnetic field regions live longer than those in the region free from magnetic field regions.
\end{abstract}

\section{INTRODUCTION}

Leighton, Noyes and Simon (1962) discovered these large cells from the velocity grams obtained during the summer of 1960 and 1961. Subsequently Simon and Leighton (1964) showed that there is similarity in the appearance of calcium $\mathrm{K}$ network and supergranular cells. Singh and Bappu (1981) used a technique to measure the individual cells to study the dependence of cell size on solar cycle. To understand the evolution and decay of these large convective cells we have obtained a continuous sequence of ionized calcium K-line filtergrams during the local summer of 1989-90. We have analysed these data to determine the mean life time of the supergranulation and relation between the life time and size of the calcium network.

\section{DATA ANALYSIS AND RESULTS}

A $15 \mathrm{~cm}$ aperture heliostat was installed at Maitri by a three member team of Jagder Singh, G.S.D.Babu and Wahab Uddin. Using an objective of $300 \mathrm{~cm}$ focal length and a narrow band 
'Daystar' filter we recorded calcium K-line filtergrams with an interval of 10 minute and spatial resolution of 2 arcsec. The enlarged photographic prints of $283 \mathrm{~mm}$ size of each filtergram belonging to the time sequence of 106 hours were prepared. Then well defined cells were marked by Mr.B.S.Nagabhushana as explained earlier by Singh and Bappu (1981) and recognised from one frame to the other. The life time of the cell was determined by visual examination of the filtergrams. The area of each cell was measured by using $\mathrm{mm}$ grid and corrected for foreshor tening.

From the freouency distribution of these cells as a function of life time one finds that most probable life time of supergranule is about 20 hours. The graphs of life time versus cell size have been plotted (not shown here due to lack of space). A linear fit to these data points has been computed. The value of correlation coefficient is 0.84 . The data indicates that life time of a cell depends on its size and is larger for bigger cells. The result of similar analysis done for the cells associated with remanent magnetic field regions show that life time is reiated to the size of the cell as in case of quiescent region. In addition the cells associated with active regions live longer than corresponding cells in the quiescent regions. One is tempted to think that remanent magnetic field restrict the flow of material from the centre of the cell to the boundaries. Of course one will need the velocity measurements to conclude these observations. Probably magnetic field reduces the rate of diffusion in the cells associated with active regions. To conclude we may say that

1. Most probable life time of calcium $\mathrm{K}$ network is about 20 hours.

2. Life time varies with size of the cell and is longer for the bigger cells.

3. The cells (of given size) associated with active region live longer than those in quiescent regions.

\section{REFERENCES}

Leighton,R.B., Noyes, R.W. \& Simon,G.W. 1962, Ap. J. 135, 474. Simon,G.W. \& Leighton, R.B. 1964, Ap. J. 140, 1120.

Singh,J. \& Bappu,M.K.V. 1981, Solar.Phys. $71,161$. 